LA WRENCE LIWEAMCAE WATIONAL LABOAATOAY

Nuclear Fuel Leasing, Recycling and Proliferation: Modeling a Global View

V. H. Reis, Hicks \& Associates, Inc.

M. P. Crozat, Hicks \& Associates, Inc.

J-S. Choi, Lawrence Livermore National

Laboratory

R. Hill, Argonne National Laboratory

March 2004 
This document was prepared as an account of work sponsored by an agency of the United States Government. Neither the United States Government nor the University of California nor any of their employees, makes any warranty, express or implied, or assumes any legal liability or responsibility for the accuracy, completeness, or usefulness of any information, apparatus, product, or process disclosed, or represents that its use would not infringe privately owned rights. Reference herein to any specific commercial product, process, or service by trade name, trademark, manufacturer, or otherwise, does not necessarily constitute or imply its endorsement, recommendation, or favoring by the United States Government or the University of California. The views and opinions of authors expressed herein do not necessarily state or reflect those of the United States Government or the University of California, and shall not be used for advertising or product endorsement purposes.

This work was performed in part under the auspices of the U.S. Department of Energy by University of California, Lawrence Livermore National Laboratory under Contract W-7405-Eng48. 
UCRL-TR-203085

\title{
DRAFT
}

3/9/04

\section{Nuclear Fuel Leasing, Recycling and Proliferation: Modeling a Global View ${ }^{1}$}

\author{
Victor H. Reis (Hicks \& Associates, Inc) \\ Matthew P. Crozat (Hicks \& Associates, Inc) \\ Jor-Shan Choi (Lawrence Livermore National Laboratory) \\ Robert Hill (Argonne National Laboratory)
}

\section{Introduction}

On February 11, 2004, U.S. President George W. Bush, in a speech to the National Defense University stated ${ }^{2}$ :

"The world must create a safe, orderly system to field civilian nuclear plants without adding to the danger of weapons proliferation. The world's leading nuclear exporters should ensure that states have reliable access at reasonable cost to fuel for civilian reactors, so long as those states renounce enrichment and reprocessing. Enrichment and reprocessing are not necessary for nations seeking to harness nuclear energy for peaceful purposes."

This concept would require nations to choose one of two paths for civilian nuclear development: those that only have reactors and those that contain one or more elements of the nuclear fuel cycle, including recycling. "Fuel cycle" states would enrich uranium, manufacture and lease fuel to "reactor" states and receive the reactor states' spent fuel. All parties would accede to stringent security and safeguard standards, embedded within a newly invigorated international regime. Reactor states would be relieved of the financial, environmental (and political) burden of enriching and manufacturing fuel and dealing with spent fuel. Fuel cycle states would potentially earn money on leasing the fuel and perhaps on sales of reactors to the reactor states.

Such a leasing concept is especially interesting in scenarios which envision growth in nuclear power, and an important consideration for such a nuclear growth regime is the role of recycling of civilian spent fuel. Recycling holds promise for improved management of spent fuel and efficient utilization of resources, but continues to raise the specter of a world with uncontrolled nuclear weapons proliferation.

If done effectively, a fuel-leasing concept could help create a political and economic foundation for significant growth of clean, carbon-free nuclear power while providing a mechanism for significant international cooperation to reduce proliferation concern. This would extend the spirit of President Eisenhower's "Atoms for Peace" vision toward solving some of the major international problems of the $21^{\text {st }}$ Century - global climate change and the creation of a peaceful and stable world political regime. 
Needless to say, this is a very complex problem, encompassing all of the issues involved in nuclear power - economics, proliferation, waste management and safety - and a myriad of public and diplomatic policy issues as well. To gain a better understanding of the leasing concept we have built an interactive system dynamics model, Multinuke, using STELLA software. ${ }^{4}$ (STELLA is particularly useful for this type of analysis because of its capability to create user-friendly interfaces.) Multinuke simulates two separate nuclear entities and possible interactions between them, and therefore can be used to investigate the fuel- leasing concept. In this paper we will apply the results of Multinuke to a few simplified scenarios to help understand how fuel leasing might affect the future global growth of nuclear power, proliferation concern and spent fuel management.

\section{The Multinuke Model}

For each separate nation state, or collection of states Multinuke assumes that the market fraction of nuclear power represents a reflection of government policy. Each entity is represented by all or part of the hybrid fuel cycle stock-and-flow diagram shown in Figure 1. Multinuke includes both thermal and fast reactors each potentially operating with both open and closed fuel cycles, and includes the option of using excess nuclear weapons material as fuel stock for both thermal and fast reactors. It tracks uranium, plutonium and fission products as they move through the cycle. Specific fuel cycles representing various policy, technology or economic choices can be represented by switching on or off various elements of the flow diagram within the program and in particular, Multinuke is designed to calculate the effects of leasing fuel services from a fuel cycle state to the reactor state by permitting material flows from one entity to the other. The outputs of the simulation are time histories of material flows, costs and proliferation concern.

For purposes of this analysis we have we have assumed the primary purpose of recycling is for spent fuel management and have configured Multinuke accordingly. If there is no limit to spent fuel storage, then there is no recycling and each nuclear entity continues to operate with an open fuel cycle. If there is a limit on spent fuel storage (assumed to be the sum of interim storage and permanent disposition) then recycling is assumed to start at such a time, and with such a capacity (tonnes/year) that the spent fuel storage limit is not exceeded during the simulation time.

Multinuke can be used to investigate possible interactions between any two entities - say Russia and Iran - or various public or private consortia, or, as we shall do in this paper, investigate the global consequences of an international leasing regime. 
UCRL-TR-203085

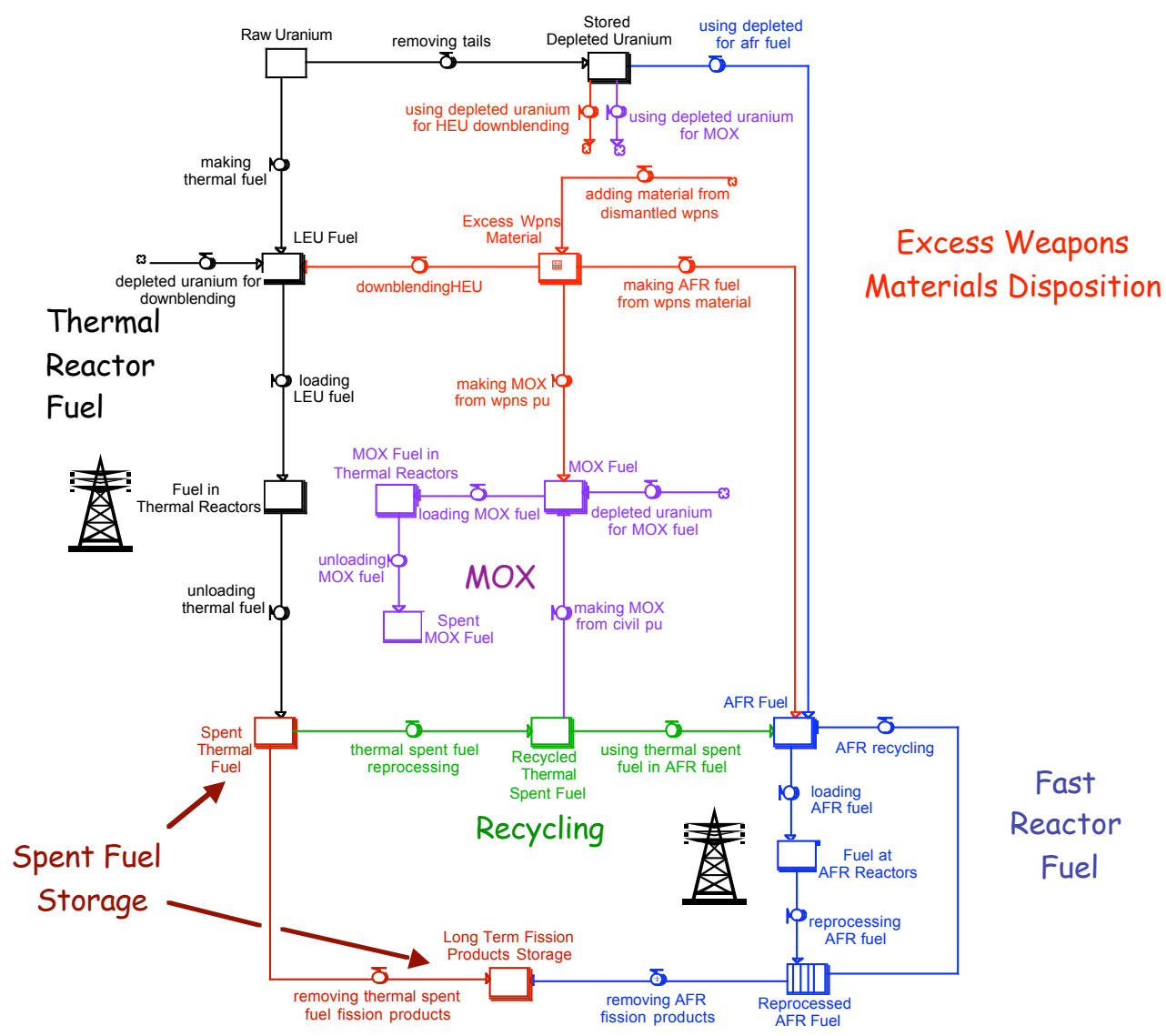

Figure 1 Multinuke Fuel Cycle Stock \& Flow Diagram

\section{Examples}

To get a sense of the possible effects of nuclear fuel leasing, we divide the world's nuclear power generating states into two categories: states that have significant fuel cycle capacity - any or all of enrichment, recycling or spent fuel storage - (Type 1), and states that have little, or no fuel cycle capability (Type 2). For purposes of this paper we take Type 1 states to be the current declared nuclear weapons states (United States, United Kingdom, France, Russia and China) plus Japan, and Type 2 states are all others. We assume electricity growth is $1 \%$ per year in Type 1 states and $2 \%$ per year in Type 2 states throughout an 80-year simulation period. Initial values for fossil power, nuclear power, and spent fuel are taken from Energy Information Administration compilations, and are shown in Table 1.

Table 1 Initial Values

$\begin{array}{ll}\text { Type } 1 & \text { Type } 2\end{array}$

\begin{tabular}{|l|c|c|}
\hline Nuclear Power (GWe/yr) & 220 & 100 \\
\hline Fossil Power (GWe/yr) & 560 & 700 \\
\hline Spent Fuel (tonnes) & 150,000 & 75,000 \\
\hline
\end{tabular}


We assume that there is 200 tonnes of civilian separated plutonium from reprocessing operations in Type 1 states. For simplicity, in this paper we ignore the disposition of excess nuclear weapons material (both HEU and plutonium) and similarly ignore the current use of reprocessing and MOX fuel for thermal reactors for Type 1 states.

To help understand the effect of nuclear fuel leasing and recycling spent fuel, we consider an aggressive nuclear power growth scenario. (Such a scenario could be driven a policy in which nuclear power is used to reduce carbon emissions from fossil electric power generators). We assume both types of states add nuclear power until they reach $50 \%$ of their total electricity generation: in 30 years for Type 1 states and in 50 years for Type 2 states, and continue to maintain nuclear power at the $50 \%$ level. The distribution of electric power is shown in Figure 2; note the Type 2 states produce the larger fraction of nuclear power after year 30 .

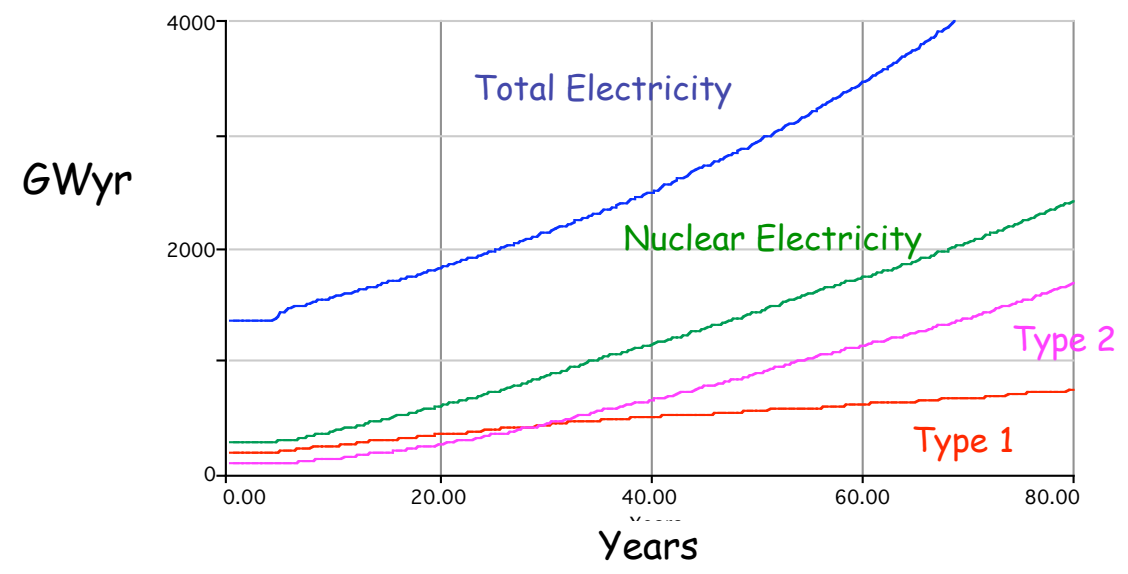

Figure 2 Assumed Electricity and Nuclear Power Growth

To examine the effects of fuel leasing and recycling on fuel management and proliferation, we consider four cases:

1. All states use thermal reactors in open cycles and do not lease. There is no limit on the amount of spent nuclear fuel. This fuel cycle is sketched in Figure 3. 
Type 2 State
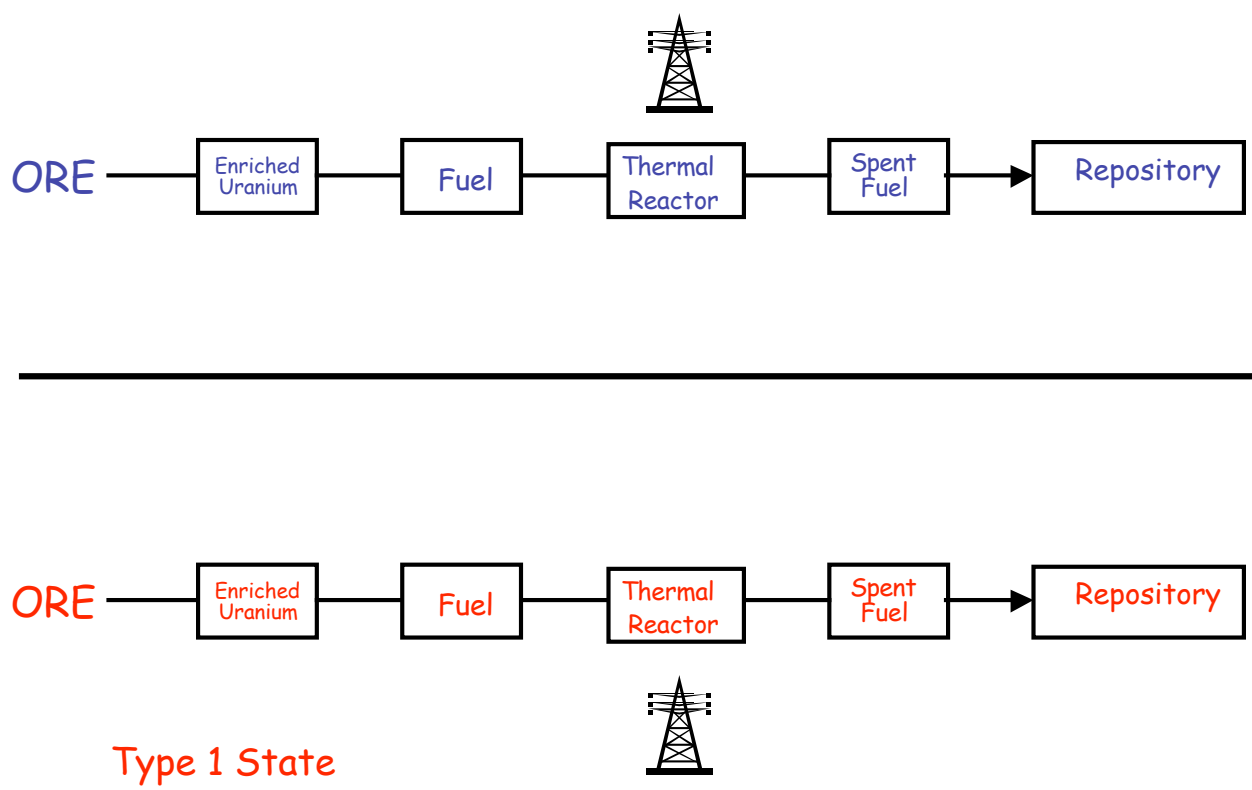

Figure 3 Fuel Cycle Diagram, Open Cycle, No Lease

2. Type 1 states have thermal reactors in an open cycle, and leases fuel to Type 2 states, which only have reactors, Figure 4 . There is no limit on the amount of spent nuclear fuel. This approach has been suggested in the recent MIT study. ${ }^{5}$

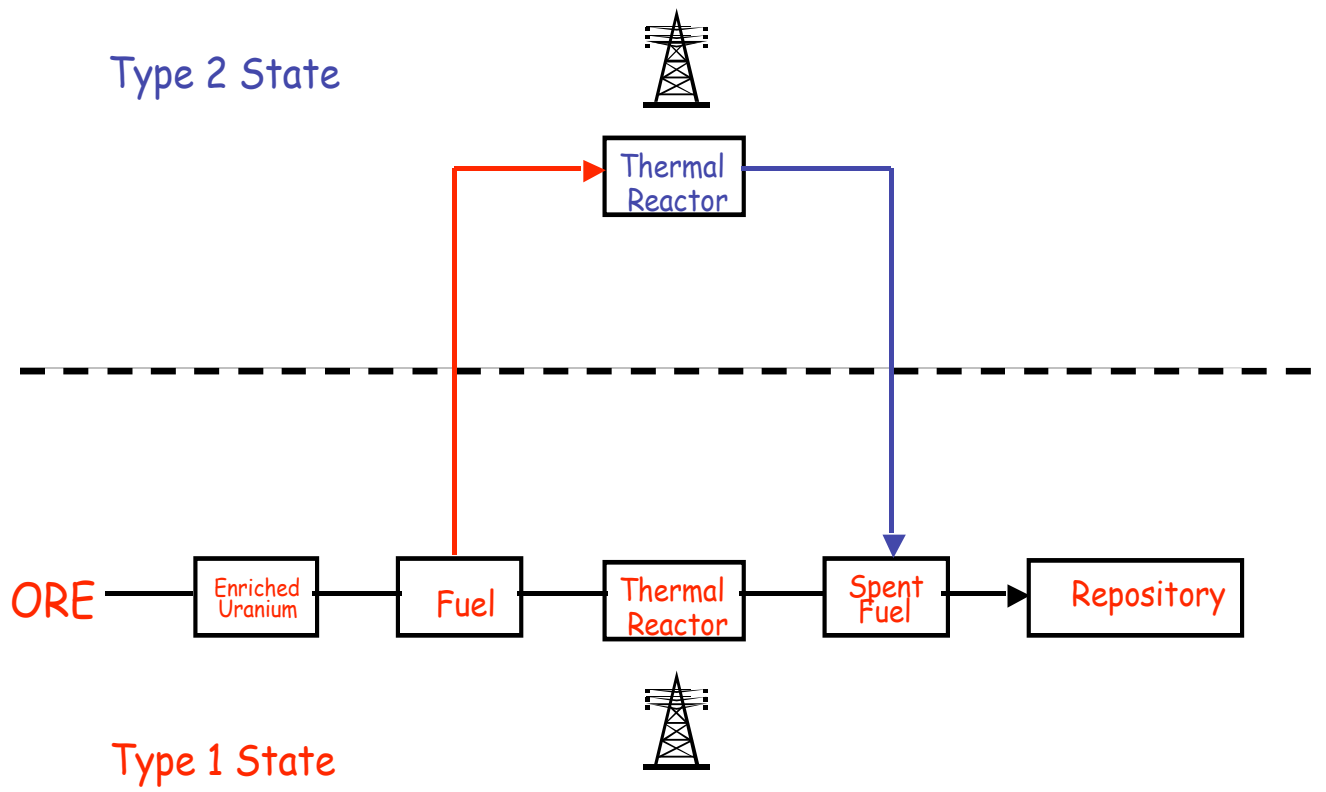

Figure 4 Fuel Cycle Diagram, Open Cycle, Lease 
3. Both types have closed fuel cycles, reprocessing to avoid an assumed limit on spent fuel storage, Figure 5. Type 1 states are limited to four Yucca Mountain Equivalents (YME $=70,000$ tonne) of permanent storage and four YME of interim storage, and Type 2 states are limited to four YME of permanent storage and six YME of interim storage.

Type 2 states close their fuel cycle using thermal MOX reactors. Once reprocessing starts we assume that $20 \%$ of the fuel for Type 2 new reactors is MOX. Type 1 states close their fuel cycle using fast spectrum reactors. The reprocessed fuel is used as startup fuel for fast spectrum reactors operating in a "burner" mode. The characteristics of the fast spectrum reactors are assumed to be similar to liquid metal integral fast reactors. ${ }^{6}$ Such a fuel cycle might result from the successful completion of the U.S. Department of Energy's Advanced Fuel Cycle Initiative and Generation IV reactor programs. ${ }^{7}$
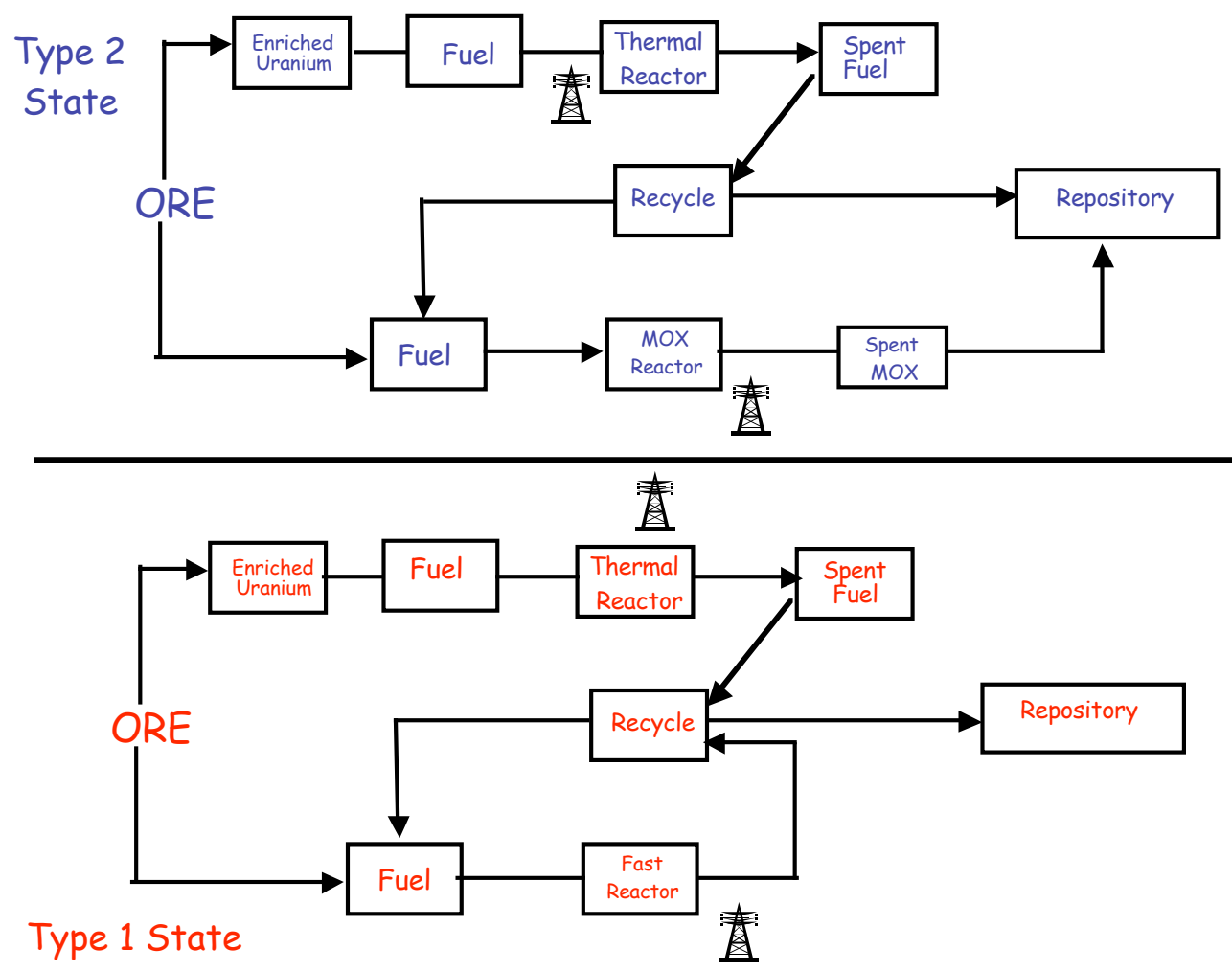

Figure 5 Fuel Cycle Diagram Closed Cycle, No Lease

4. Type 2 states lease the fuel from the Type 1 states, which operate in the closed cycle mode, again with fast reactors for burning the reprocessed thermal reactor fuel both from Type 1 and Type 2 states, Figure 6 . The net effect of the whole cycle is to convert uranium ore into electricity and fission products, while keeping spent fuel storage. 


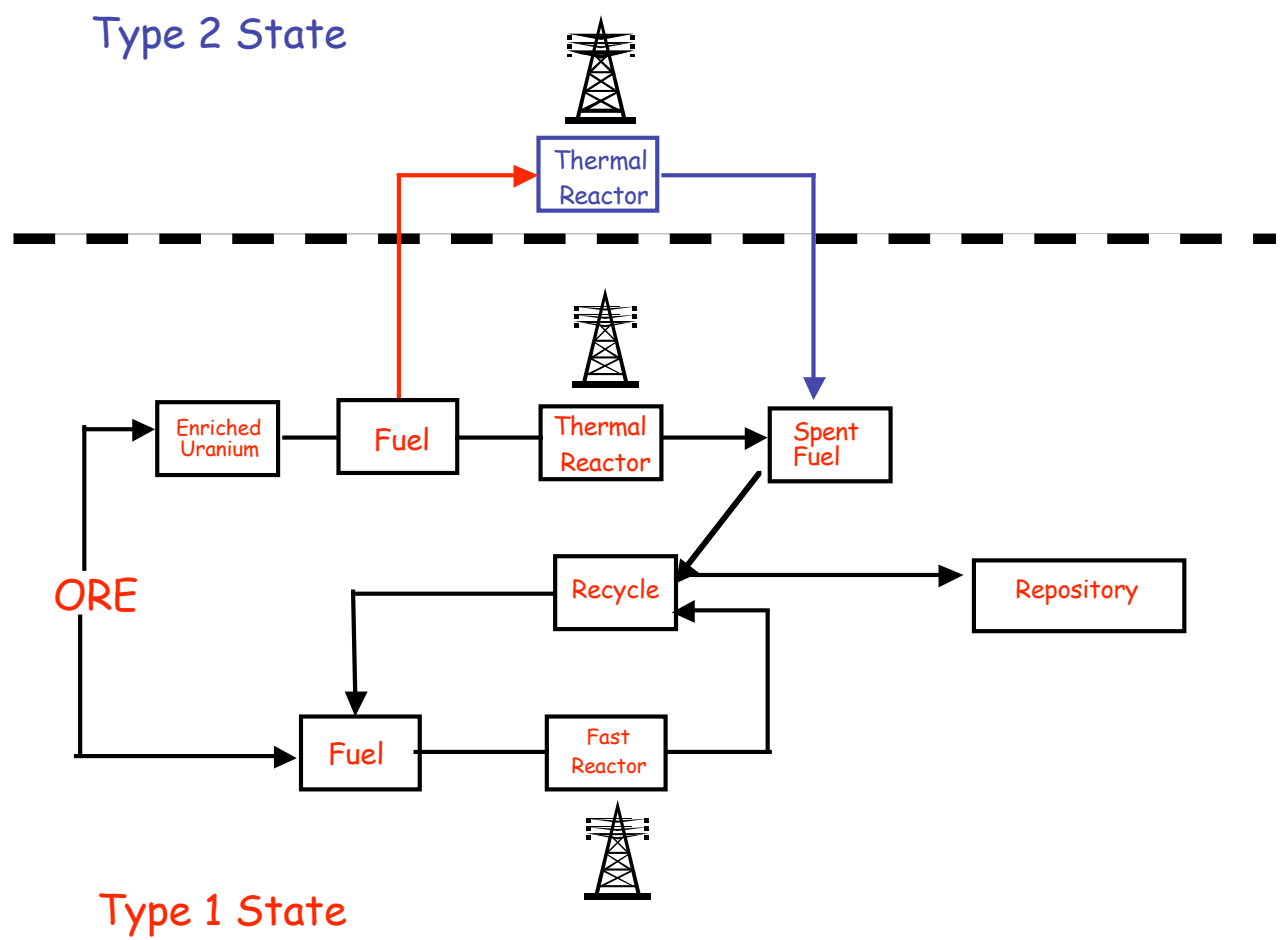

Figure 6 Fuel Cycle, Closed Cycle, Lease

\section{Nuclear Spent Fuel Storage}

Using only open thermal cycles yields a large increase in nuclear spent fuel storage (mass) requirements for the aggressive growth scenario, and if the U.S. experience is any indication, spent fuel storage could be a major impediment to nuclear power growth. Without recycling, the amount global spent fuel storage grows to very large quantities, Figure 7.

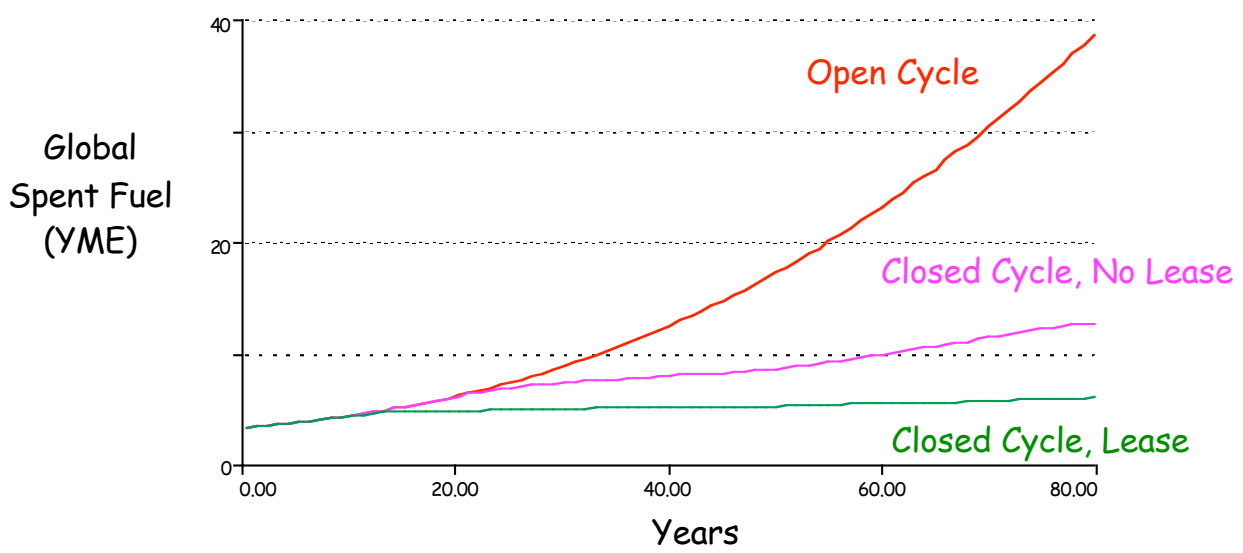

Figure 7 Spent Fuel Accumulated (Yucca Mountain Equivalents) 
Keeping the spent fuel within the limits chosen here will require prodigious amounts of reprocessing, given the presumed growth of nuclear power, Figure 8. In particular, leasing fuel from Type 2 states to Type 1 states places a large reprocessing requirement to keep to keep the spent fuel within the Type 1 storage limits. We note that the maximum estimated global reprocessing capacity in 2010 is 7600 tonnes per year. ${ }^{8}$

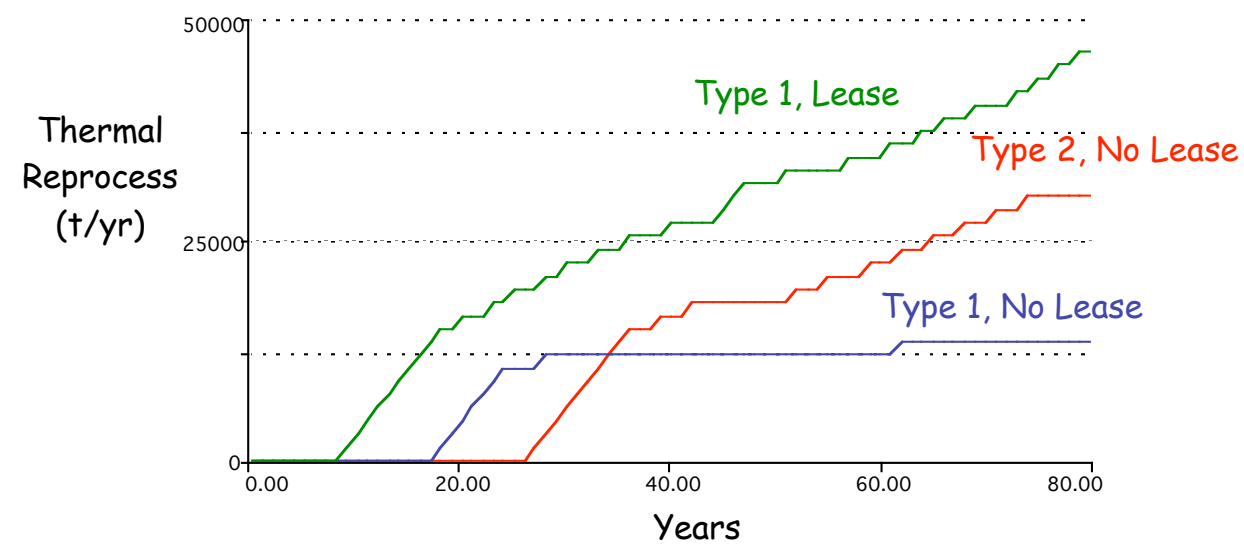

Figure 8 Required Recycle Capacity

\section{Proliferation Concern}

Estimating proliferation concern is a particularly complex problem and has been the subject of numerous studies and ongoing analyses ${ }^{9}$. One approach to proliferation concern is to use an index that connects the amount of fissile material within the fuel cycle to its potential for being manufactured into a weapon, the level of security and safeguards, and the state's latent desire to divert nuclear material into nuclear weapons. This starts by defining a "weapons potential" (W) for all the material within the fuel cycle, i.e.:

The weapons potential $\left(\mathrm{W}_{\mathrm{i}}\right)$ of a mass of material in form (i) is taken to be:

Where

$$
\mathrm{W}_{\mathrm{i}}=\square_{\mathrm{j}} \mathrm{M}_{\mathrm{ij}} \mathrm{C}_{\mathrm{ij}} \mathrm{T}_{\mathrm{ij}} / \mathrm{Q}_{\mathrm{j}}
$$

$$
\begin{aligned}
& \mathrm{j}=1 \text {, Plutonium, } \mathrm{j}=2 \text {, Uranium } 235 \\
& \mathrm{M}_{\mathrm{ij}}=\text { Mass of fissile material in form (i) }(\mathrm{kg}) \\
& \left.\mathrm{C}_{\mathrm{ij}}=\text { Composition factor (how easy is a material to handle }-0 \text { to } 1\right) \\
& \mathrm{T}_{\mathrm{ij}}=\text { Technology factor (how easy is it to manufacture into a weapon }-0 \text { to } 1 \text { ) } \\
& \mathrm{Q}_{\mathrm{j}}=\text { "Significant Quantity" of fissile material }\left(8 \mathrm{~kg} \text { for Pu, } 25 \mathrm{~kg} \text { for } \mathrm{U}^{235}\right)
\end{aligned}
$$

Thus the unit of weapons potential is "equivalent nuclear weapons significant quantity." 
We distinguish between two forms of proliferation concern: latent concern and security concern. The "latent" concern, or the concern about a nation's capability to deliberately convert its civilian nuclear program into a weapons program - either overtly or covertly is estimated as:

$$
\text { Latent Concern }=(\text { Breakout Concern })(1-\mathrm{S})\left(\square_{\mathrm{i}}\left(\mathrm{W}_{\mathrm{i}}\right)\right)
$$

Where $\mathrm{S}$ is the level of overall national level of safeguards, a number from 0 to $1^{10}$. The breakout concern, also a number from 0 to 1 , is essentially a political (and intelligence) judgment about a state's current proclivity to develop weapons from its civilian nuclear power program. Declared nuclear weapons states would have a Breakout Concern of 0 , since they already have nuclear weapons. North Korea, for example, would most likely be judged to have a Breakout Concern of 1 by the United States, perhaps something less by China.

The security concern represents the ability of a nation to keep its nuclear material secure from theft or sabotage, so is particularly applicable to terrorist threats.

$$
\text { Security Concern }=\left(\square_{\mathrm{i}}\left(\mathrm{W}_{\mathrm{i}}\right)\left(1-\mathrm{P}_{\mathrm{i}}\right)\right)
$$

Where $\mathrm{P}_{\mathrm{i}}$ is the protection level of the material in form (i). We take the total proliferation concern to be the sum of the latent and security concerns.

To get a sense of how the leasing concept affects nuclear material proliferation concern, we have assumed the following for the weapons composition and technology factors, Table 2, and breakout concern, safeguard and security factors in Table 3.

Table 2 Nuclear Material Proliferation Factors

\begin{tabular}{|l|l|l|}
\hline Material & $\begin{array}{l}\text { Composition } \\
\text { Factor }\end{array}$ & $\begin{array}{l}\text { Technology } \\
\text { Factor }\end{array}$ \\
\hline MOX Fuel & 0.8 & 0.9 \\
\hline Spent MOX Fuel & 0.8 & 0.3 \\
\hline Separated Civil Pu & 0.8 & 1 \\
\hline Spent Thermal Fuel & 0.8 & 0.3 \\
\hline Thermal Fuel (LEU) & 0.3 & 0.3 \\
\hline Fast Reactor Fuel & 0.8 & 0.9 \\
\hline Spent Fast Reactor Fuel & 0.8 & 0.3 \\
\hline
\end{tabular}


Table 3 Latent \& Security Proliferation Factors

\begin{tabular}{|l|l|l|l|}
\hline & Type 1 & $\begin{array}{l}\text { Type 2 } \\
\text { No Lease }\end{array}$ & $\begin{array}{l}\text { Type 2 } \\
\text { Lease }\end{array}$ \\
\hline Breakout Concern & 0 & 0.2 & 0.2 \\
\hline Safeguard & 0.95 & 0.8 & 0.95 \\
\hline Security & 0.9 & 0.9 & 0.9 \\
\hline
\end{tabular}

The composition values are all relative to pure weapons grade plutonium and uranium, the security values are relative to the security typical at a weapons facility, and represent informed judgment, not detailed analysis. A Breakout Concern of 0.2 means that $20 \%$ of all the material Type 2 states is considered to be in states that may be possible candidates for becoming weapon states. Again, this may vary depending on who is making the calculation.

Calculations of the global weapons concern at 50 years time for the four different cases are shown in Figure 9, compared with the global weapons concern of the current stockpile of fissile material.

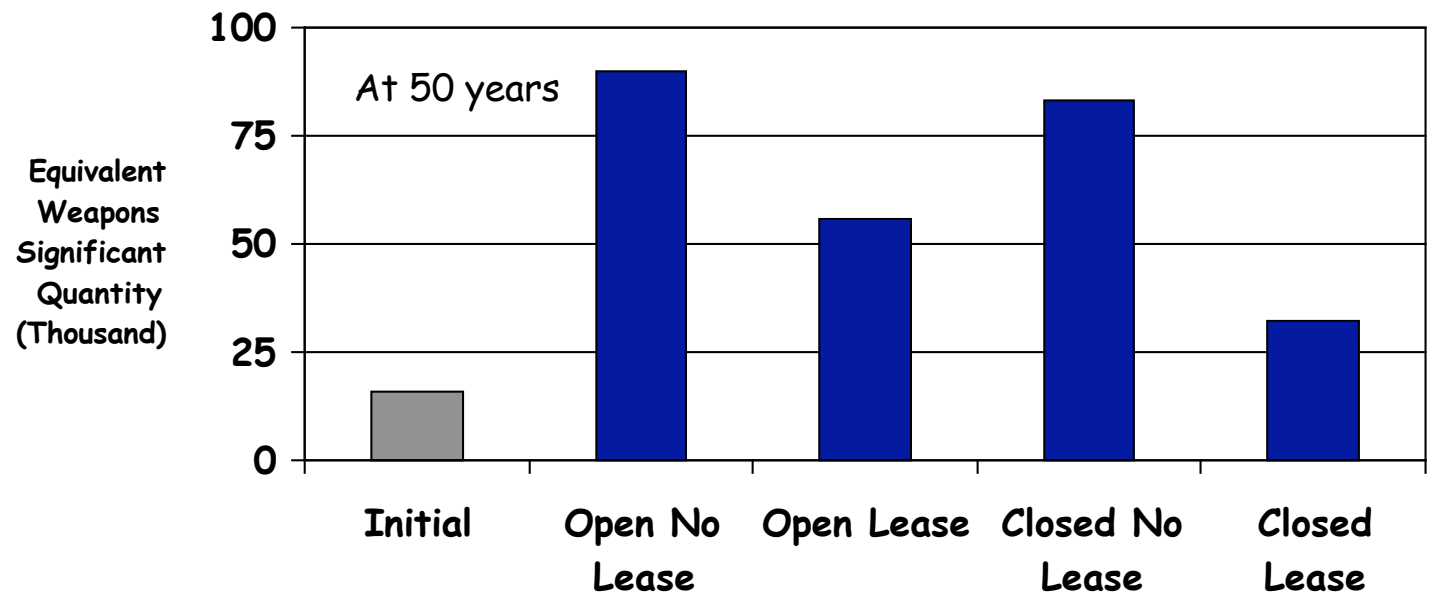

Figure 9 Global Proliferation Concern

First, we note that the global weapons concern is a very large number will increase in the growth scenarios. (Recall the total number of nuclear weapons during the height of the Cold War has been estimated to be around 80,000, most of them much more powerful than assumed here. $)^{11}$ The current global level of nuclear power generation contains a lot of fissile material and there will be a lot more if nuclear power grows to a level assumed here. Nonetheless, the effect of leasing can significantly reduce proliferation concern for both open and closed cycles, and reprocessing approaches can be conceived of that reduce, rather than increase proliferation concern. This reduction in proliferation concern results from the shifting of nuclear material from Type 2 nations, (breakout concern of 0.2 ) to Type 1 nations, (breakout concern 0 ). Recycling causes a further reduction in 
proliferation potential in the later years, because it reduces large quantities of stored spent fuel, which remain a security concern even in Type 1 states.

Analyzing proliferation concern from a global weighted nuclear material basis provides a useful perspective, but tends to mask some specific important proliferation issues. Two such issues are the enrichment capability that would be necessary to provide fuel for Type 2 states if they choose not to lease fuel and in the possible generation of separated, "cool" plutonium as an intermediate product in recycling.

Enrichment capability as a path to nuclear weapons has been a particular concern recently as North Korea, Iraq, Libya and Iran were discovered (or admitted) to have clandestine enrichment programs, and separated civilian plutonium continues to generate proliferation concern because of its relative ease in transforming it into usable weapons. ${ }^{12}$ Figure 10 shows the potential weapons production capacity inherent in Type 2 states, if they embark on the civilian growth paths assumed here, and they do not lease.

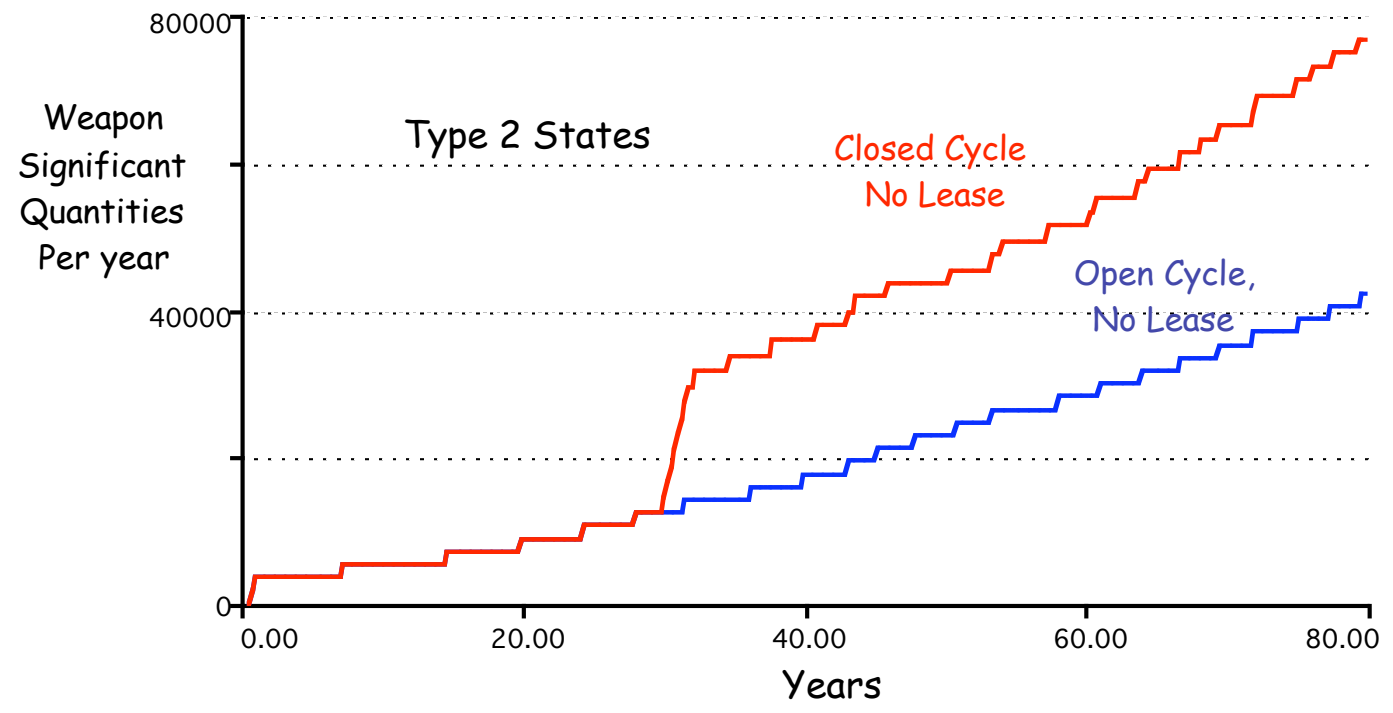

Figure 10 Potential Type 2 State Weapons Production Capacity

Separated civilian plutonium is frequently taken to be a particular proliferation concern from the perspective of potential terrorist use. For the simplified material flow model assumed here, the large reprocessing capacities of the closed fuel cycles yield significant quantities of recycled plutonium, Figure 11. Without leasing the plutonium builds up rapidly in Type 2 states once the limit on spent fuel is reached, and can reach large values for Type 1 states as well. This concern has been one of the motivations for the development of the integral fast reactor, which uses a reprocessing technique pyroprocessing - that does not separate plutonium from the other actinides, remains highly radioactive, and thus produces a product that is much more difficult to turn into a weapon. This development would be particularly significant if the leasing concept was 
put into operation because of the large amount of material to be processed and the continuing security concerns in Type 1 states.

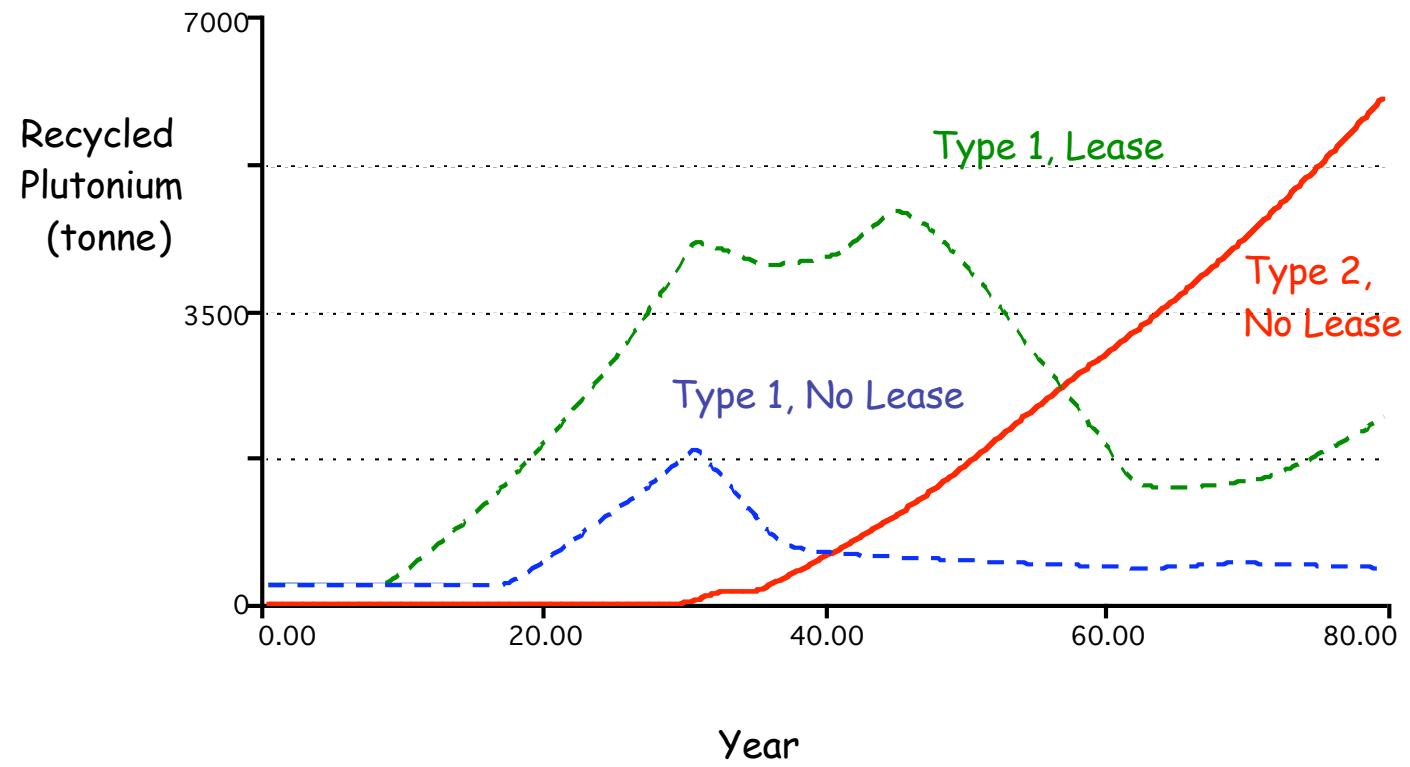

Figure 11. Recycled Plutonium for Closed Cycle Examples

\section{Economic Considerations}

Finally we must consider under what conditions the leasing deal makes economic sense for both Type 1 and Type 2 states. At what leasing price will it be less expensive for the Type 2 state to lease rather than to develop and run its own fuel cycle? Multinuke uses a very simplified cost model: each facility has a fixed cost and an operating cost based upon material throughput. For reactors, the fixed cost includes overnight construction and "cost-of-money" elements, both of which are accrued when the facility goes on line. We have assumed a loan period of 20 years and an interest rate of 5\% for Type 1 states and $8 \%$ for Type 2 states.

\section{Table 4 Cost Parameters}

\begin{tabular}{|l|l|l|}
\hline Facility & Fixed Cost & Operating Cost \\
\hline Thermal Reactor & $\$ 1400 / \mathrm{kW}$ (overnight) & $1.4 \phi / \mathrm{kWhr}$ \\
\hline Fast Reactor & $\$ 2000 / \mathrm{kW}$ (overnight) & $0.7 \phi / \mathrm{kWhr}$ \\
\hline $\begin{array}{l}\text { Enrichment \& Fuel } \\
\text { Manufacture }\end{array}$ & $\$ 4 \mathrm{~B} / 10 \mathrm{M} \mathrm{kg}-\mathrm{SWU}$ & $\begin{array}{l}\$ 100 / \mathrm{kg}-\mathrm{SWU} \\
\$ 600 / \mathrm{kg} \text { fuel fab }\end{array}$ \\
\hline $\begin{array}{l}\text { Reprocessing \& Pu Fuel } \\
\text { Manufacture }\end{array}$ & $\begin{array}{l}\$ 6 \mathrm{~B} / 2500 \mathrm{t} \text { spent } \\
\text { fuel/yr }\end{array}$ & $\$ 0.5 \mathrm{M} / \mathrm{t}$ spent fuel \\
\hline Interim Storage & & $\$ 400 / \mathrm{kg}$ spent fuel \\
\hline Permanent Storage & $\$ 48 \mathrm{~B} / \mathrm{YME}$ & \\
\hline
\end{tabular}


We calculate an average cost of electricity over the time of the simulation by integrating the total cost of the electricity generated, divided by the total electricity generated. This is essentially equivalent to a "going-forward levelized cost" that is related to the levelized const metric often used to analyze financial decisions. ${ }^{13}$ Figure 12 indicates that a fuel services lease price of around $\$ 2000$ per kilogram represents a break-even cost for both the Type 1 " fuel cycle" state and the Type 2 "reactor" state.

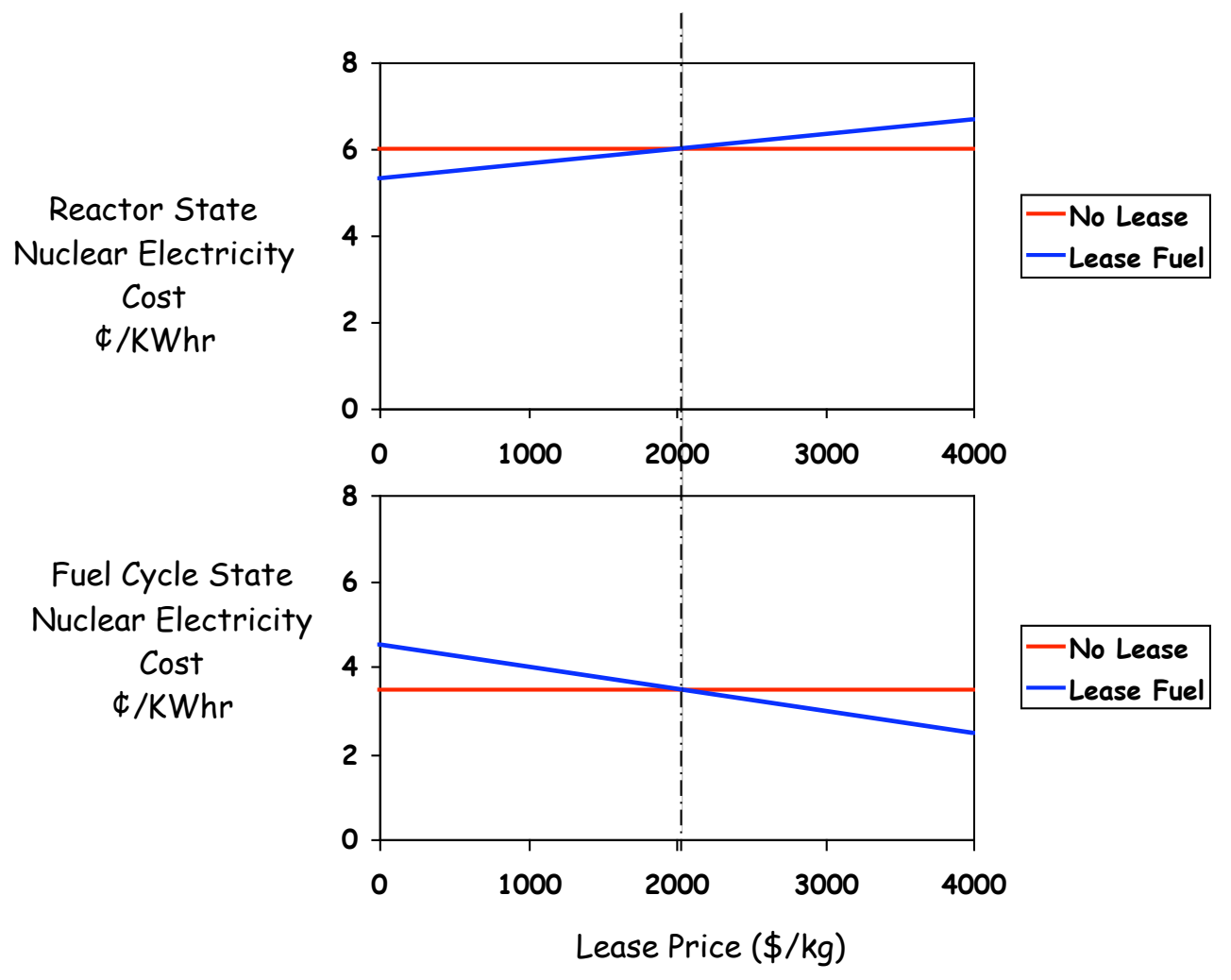

Figure 12 Levelized Electricity Costs and Lease Price Comparison

\section{Discussion}

The purpose of this paper was to demonstrate how a relatively simple system dynamic model can be used to investigate an innovative multi-state fuel cycle concept, helping to elucidate how and why different policy perspectives influence potential outcomes. The cases examined here represent only a narrow range of possible nuclear technology developments and the values assumed for many important parameters are at best rough estimates. Further, some of the issues described - energy generation, nuclear fuel storage and proliferation - are perhaps better attacked at the national or commercial level as opposed to global regime. Nonetheless, the results illuminate some important connections with respect to the possibility of nuclear fuel leasing. Starting from the top:

1) If nuclear power to have a meaningful impact on the reduction of carbon emissions from electricity generation, a significant fraction of electricity 
generation must come from nuclear power plants. This will require a global nuclear enterprise many times larger than currently exists.

2) Supplying this nuclear power with current-technology thermal reactors in an open fuel cycle will generate a considerable amount of spent fuel. Disposing of this fuel represents a continuing political as well as technical issue.

3) One approach to reducing the amount of spent fuel would be to reprocess the thermal spent fuel into start-up fuel for new fast reactors. If possible, reprocessing should be accomplished without adding to separated plutonium stocks, a continuing security and proliferation concern.

4) A major increase in nuclear power generation will also increase nuclear security and proliferation concern. Fuel leasing from states that have low latent proliferation concern to states that have high latent proliferation concern could help reduce overall proliferation concern, especially when coupled with an improved security and safeguard regime.

5) The more fuel leasing can be made economically viable for both parties to the arrangement, the less discriminatory or coercive it would appear to be, and the more likely it could be accepted as part of an international regime.

In short, it appears that the fuel-leasing concept could be a plausible approach to restraining the growth of proliferation concern while pursuing a significant expansion of nuclear power. Needless to say, creation of such a new nuclear regime represents a significant challenge to the international community, to say nothing of the technical, political and economic hurdles, but if the results of this analysis are at all indicative, it also represents a significant opportunity to extend President Eisenhower's "Atoms for Peace" vision beyond the Cold War and into the next century.

\footnotetext{
${ }^{1}$ An oral version of this paper was presented at the American Nuclear Society/European Nuclear Society embedded meeting Global 2003, Atoms for Peace and Prosperity, New Orleans LA, November 17, 2003

${ }^{2}$ http://www.whitehouse.gov/news/releases/2004/02/20040211-4.html

${ }^{3}$ In addition to President Bush's speech, see also the December 22, 2003 New York Times Op-Ed, Good Nukes, Bad Nukes by Carter, Kanter, Perry and Scowcroft and Robert Einhorn in Proliferation Challenges after Iraq, Eisenhower National Security workshop, co-sponsored by the Woodrow Wilson International Center and the Reves Center for International Studies of the College of William and Mary, Dec 2003. A more detailed approach to this concept is developed in the paper by J. Choi and T. Isaacs, Toward A New Nuclear Regime, Preprint UCRL-JC-151485, May 2003. It is also
} 
recommended in the MIT study, The Future of Nuclear Power 2003, though the authors of that report state that a cost effective technology for spent fuel reprocessing might be decades away.

${ }^{4}$ Stella is a product of isee systems: http://www.hps-inc.com.

${ }^{5}$ The Future of Nuclear Power Massachusetts Institute of Technology, 2003

${ }^{6}$ Hill, Wade, Liaw and Fujita, " Physics Studies of Weapons Plutonium Disposition in the Integral Fast Reactor Closed Fuel Cycle," Nuclear Science and Engineering: 121,1731 (1995).

${ }^{7}$ See the Department of Energy, Office of Nuclear Energy's website, http://nuclear.gov/

${ }^{8}$ Albright, Berkhout and Walker, Plutonium and Highly Enriched Uranium 1996 World Inventories, Capabilities and Policies. Oxford University Press, 1997.

${ }^{9}$ Proliferation Analysis

${ }^{10}$ We could easily extend the analysis to estimating the safeguards for each separate portion of the fuel cycle, but we have assumed that the safeguard system has been balanced.

${ }^{11}$ Schwartz, ed., Atomic Audit: The Costs and Consequences of U.S. Nuclear Weapons Since 1940. Brookings Institution Press, 1998.

${ }^{12}$ Civil Separated Plutonium Stocks - Planning for the Future. Proceedings of the March 14-15, 2000 Conference. Institute for Science an International Security.

${ }^{13}$ The difference in levelized fuel cycle costs between Type 2 and Type 1 states is related to the fact that Type 1 states have are assumed to have a substantial nuclear infrastructure at the start of the simulation for which the costs have already been paid. 